\title{
EXECUTIVE FUNCTION AND ACADEMIC PERFORMANCE AMONG TAIWANESE STUDENTS IN HIGHER EDUCATION: A CORRELATIONAL STUDY
}

\author{
Shuan-Ju Hung \\ Graduate Institute of Education, Providence University, Taichung, Taiwan
}

\begin{abstract}
The purpose of this study was to investigate the associations between EF components (i.e., working memory and inhibition) and academic performance among Taiwanese students in higher education. Participants were 54 students from an educational psychology course at a private university in central Taiwan. Their EF was measured by the Adult Executive Functioning Inventory (ADEXI) and academic performance was measured by three scores: midterm exam score, final exam score and total score. Pearson's correlational coefficient was computed to assess the correlations between EF components and academic performance in the current sample. Statistical significance for data analysis was set at $p<.05$. No significant correlations were found between the subscale of working memory and midterm scores $(r=.045, p=.749)$, final exam scores $(r=.129, p=.351)$ and total scores $(r=.092, p=.509)$. Similarly, the associations of the subscale of inhibition with midterm scores $(r=-.200, p=.148)$, final exam scores $(r=-.225, p=.102)$ and total scores $(r=$ $.222, p=.107)$ were not statistically pronounced. Although significant associations between the components of EF and academic performance in our sample were not observed, several explanations for the findings and implications for future research were provided.
\end{abstract}

Keywords: academic performance; executive function; correlational study; higher education

\section{Introduction}

From the perspective of developmental neuropsychology, Welsh and Pennington (1988) defined executive function (EF) "as the ability to maintain an appropriate problem-solving set for attainment of a future goal." The components involved in this set included: "(a) an intention to inhibit a response or to defer it to a later more appropriate time, (b) a strategic plan of action sequences, and (c) a mental representation of the task, including the relevant stimulus information encoded into memory and the desired future goal-state" (pp. 201-202). So far, although the agreement among researchers is not yet reached as to whether EF is a unitary construct with interrelated components or consists of separable components (Garon, Bryson, \& Smith, 2008; Miyake et al., 2000), three major components have been frequently postulated in studies, which are working memory, inhibition, and set shifting. Working memory is described as a system that stores information in mind and manipulates information in response to cognitive tasks. Inhibition is defined as an ability to withdraw dominant responses to events. Set shifting is described as an ability to switch between mental sets in response to external changing goals (Garon et al., 2008).

There is much substantial evidence that EF plays an important role in academic performance or school achievement from early childhood to adolescence (Ahmed, Tang, Waters, \& Davis-Kean, 2019; Best, Miller, \& Naglieri, 2011; Blair, 2016; Micalizzi, Brick, Flom, Ganiban, \& Saudino, 2019; Montoya et al., 2019). For example, Fuhs, Farran, and Nesbitt (2015) found that children's EF skills, which were rated by teachers and direct assessments at the beginning of prekindergarten (pre-k), significantly correlated with their academic gains (i.e., literacy, language and mathematics) over the pre-k year. In a cross-sectional study with a large, representative national sample $(\mathrm{N}=2,036)$ aged 5 to 17 , Best et al. (2011) reported significant associations between complex EF and academic performance across ages. Specifically, inhibition and working memory, two 
of the major components of EF (Karr et al., 2018; Miyake et al., 2000), have been observed to make unique contributions to academic performance (e.g., Blair \& Razza, 2007; Espy et al., 2004). Using an executive function battery to assess three EF components (i.e., working memory, inhibition and shifting abilities), Espy et al. (2004) found that both working memory and inhibition were linked to preschoolers' early mathematics ability after child age, maternal education and child vocabulary were controlled for. Only inhibition made a unique contribution to mathematics ability after the aforementioned variables and other EF components were controlled (Espy et al., 2004). Similarly, in another study (Blair \& Razza, 2007), inhibition was revealed to prominently correlate with early mathematics and reading ability among 3- to 5-year olds. In a group of schoolage children, St Clair-Thompson and Gathercole (2006) demonstrated that both working memory and inhibition related to academic achievement with working memory being more strongly linked to academic performance than inhibition. Moreover, the contributions of inhibition or working memory to academic achievement are found across ethnic backgrounds, not existing in specific ethnic groups. Prior research focusing on ethnic minority groups showed that preschoolers' inhibition at age 4 displayed positive associations with their mathematics skills at age 4 and predicted their growth in such skills in the following two years after adjusting for ethnic background (Ng, Tamis-LeMonda, Yoshikawa, \& Sze, 2015). With a cross-cultural design, Thorell, Veleiro, Siu, and Mohammadi (2013) investigated the relations between EF components (i.e., inhibition and working memory) and academic achievement (i.e., mathematics and language skills) among Spanish, Swedish, Iranian, and Chinese children. Executive function was assessed by teachers and parents using a rating instrument. Their study showed that both working memory and inhibition notably correlated with academic performance, but significant associations were not observed in parenting ratings in the Chinese sample (Thorell et al., 2013).

Overall, the existing literature has documented the important contributions of EF components, inhibition and working memory, to academic achievement and lent support to the findings that individuals with deficits in EF are at risk for academic difficulties or lack of study success in school (Morgan et al., 2019).

Relative to the literature focusing on children and adolescents, there is less research on the associations between EF and academic performance among students in higher education. And, to the best of our knowledge, studies investigating the links between $\mathrm{EF}$ and academic achievement among Chinese students in higher education are even fewer as most of the studies addressing this topic are based on samples drawn from Western countries (Baars, Nije Bijvank, Tonnaer, \& Jolles, 2015; Said, 2013). For example, one study showed that no significant associations existed between EF components (i.e., inhibition and working memory) and academic achievement measured by test scores and observed study behaviors among 32 female college students from a state university in the United States (Said, 2013). Other data from a university in the Netherlands showed that better EF skills (i.e., attention, planning, and self-control and self-monitoring) were predictive of study success among first-year college students (Baars et al., 2015).

In conclusion, accumulating evidence has shown that inhibition and working memory are significantly related to academic performance in children and adolescents. However, limited is known about the associations between these two components of EF and academic performance among Chinese students in higher education. Therefore, in order to bridge the research gap and extend previous research, the current study is conducted at a Taiwan university to explore the associations between EF components (i.e., inhibition and working memory) and academic performance among students in higher education. 


\section{Methods}

\section{Participants and Procedure}

The study consists of 55 students from an educational psychology course during the academic year of $2018 / 2019$ at a private university in central Taiwan. One student was eliminated due to refusal to fill out the questionnaire, leaving a total number of 54 participants for further analysis. The mean age of this sample was 26.72 years $(\mathrm{SD}=10.62$, range $=18-50)$, with $75.9 \%$ of the participants being female and $64.8 \%$ of the participants being undergraduates. Participants' affiliated colleges were as follows: Foreign Languages and Literature (22.2\%), Humanities and Social Sciences (55.6\%), Management (16.7\%), Computing and Informatics (3.7\%), and International College (1.9\%). In the last class of the semester, the questionnaires including demographic information and the Adult Executive Functioning Inventory (ADEXI) were administered to students. Students were informed that their participation was voluntary and that data would be analyzed on group level for research purpose. The questionnaire took about 5 minute to complete.

\section{Measures}

The Adult Executive Functioning Inventory (ADEXI) is an adult version of the Child Executive Functioning Inventory (CHEXI) (Holst \& Thorell, 2018; Thorell \& Nyberg, 2008). Both the ADEXI and CHEXI have been translated into different languages (e.g., Chinese, French, Dutch, Swedish, and so on) and are free for download on the website (www.chexi.se). The ADEXI includes 14 items, which are grouped into two subscales: working memory (9 items: e.g., "I have difficulty remembering lengthy instructions") and inhibition (5 items: e.g., "I have a tendency to do things without first thinking about what could happen"). Participants are asked to circle a number indicating how well the statement is true for themselves based on a 5-point Likert scale $(1=$ definitely not true, $2=$ not true, $3=$ partially true, $4=$ true, $5=$ definitely true). The reliability and validity of the ADEXI have been well reported in the previous study (Holst \& Thorell, 2018). Coefficient alphas for the current sample were 0.80 (working memory) and 0.70 (inhibition).

Additionally, a student's academic performance was measured by three scores: midterm exam score, final exam score and total score (i.e., the average of the midterm exam score and the final exam score). The possible ranges of midterm exam scores and final exams scores were 0 to 100 .

\section{Data Analysis}

Statistical analyses including descriptive analysis, correlational analysis (i.e., Pearson's r) were performed using the SPSS Statistics 17.0 to answer the research question of the current study. For descriptive statistics, means and standard deviations were analyzed for continuous variables while numbers and percentages were presented for discontinuous variables. For correlational analysis, Pearson's correlational coefficient was computed to investigate the correlations between executive function and academic performance in the current sample. Statistical significance for data analysis was set at $\mathrm{p}<.05$ (2-tailed).

\section{Results}

Descriptive statistics of the study variables (i.e., age, sex, program, college, ADEXI score and academic performance) are presented in Table 1. Regarding participants' executive function measured by the ADEXI, the mean scores were $2.60(\mathrm{SD}=0.69$, observed rage $=1.0-3.67)$ and $2.50(\mathrm{SD}=0.54$, observed range $=1.40-4.60)$ for the subscales of working memory and inhibition, respectively. As for participants' academic performance, the mean scores of midterm exam scores, final exam scores and total scores were 77.70 (SD $=14.52$, observed range $=41-100), 74.43(\mathrm{SD}=15.05$, observed range $=48-100)$, and $76.06(\mathrm{SD}=14.15$, observed range $=46-$ 100). 
Table 1 Descriptive statistics of the sample

\begin{tabular}{|c|c|}
\hline Variable & Mean \pm SD or No. $(\%)(\mathrm{N}=54)$ \\
\hline Age (years) & $26.72 \pm 10.62$ \\
\hline \multicolumn{2}{|l|}{ Sex } \\
\hline Male & $13(24.1)$ \\
\hline Female & $41(75.9)$ \\
\hline \multicolumn{2}{|l|}{ Program } \\
\hline Undergraduate & $35(64.8)$ \\
\hline Graduate & $19(35.2)$ \\
\hline \multicolumn{2}{|l|}{ College } \\
\hline Foreign Languages and Literature & $12(22.2)$ \\
\hline Humanities and Social Sciences & $30(55.6)$ \\
\hline Management & $9(16.7)$ \\
\hline Computing and Informatics & $2(3.7)$ \\
\hline International College & $1(1.9)$ \\
\hline \multicolumn{2}{|l|}{ ADEXI } \\
\hline Working memory (observed range) & $2.60 \pm 0.69(1.0-3.67)$ \\
\hline Inhibition (observed range) & $2.50 \pm 0.54(1.40-4.60)$ \\
\hline \multicolumn{2}{|l|}{ Academic performance } \\
\hline Midterm exam score (observed range) & $77.70 \pm 14.52(41-100)$ \\
\hline Final exam score (observed range) & $74.43 \pm 15.05(48-100)$ \\
\hline Total score (observed range) & $76.06 \pm 14.15(46-100)$ \\
\hline
\end{tabular}

Note. ADEXI = Adult Executive Functioning Inventory; $\mathrm{SD}=$ standard deviation .

The correlations between executive functions and academic performance in this sample are shown in Table 2 . No significant correlations were found between the subscale of working memory and midterm scores $(\mathrm{r}=.045$, $\mathrm{p}=.749)$, final exam scores $(\mathrm{r}=.129, \mathrm{p}=.351)$ and total scores $(\mathrm{r}=.092, \mathrm{p}=.509)$. Similarly, the associations of the subscale of inhibition with midterm scores $(r=-.200, p=.148)$, final exam scores $(r=-.225, p=.102)$ and total scores $(r=-.222, \mathrm{p}=.107)$ were not statistically pronounced.

Table 2 Correlations between academic performance and the subscales of the ADEXI

\begin{tabular}{|c|c|c|c|c|c|c|}
\hline & \multicolumn{2}{|c|}{ Midterm exam } & \multicolumn{2}{|c|}{ Final exam } & \multicolumn{2}{|l|}{ Total } \\
\hline & $\mathrm{r}$ & p-value & $\mathrm{r}$ & $\mathrm{p}$-value & $\mathrm{r}$ & $\mathrm{p}$-value \\
\hline \multicolumn{7}{|l|}{ ADEXI } \\
\hline Working memory & .045 & .749 & .129 & .351 & .092 & .509 \\
\hline Inhibition & -.200 & .148 & -.225 & .102 & -.222 & .107 \\
\hline
\end{tabular}

Note. ADEXI = Adult Executive Functioning Inventory. 


\section{Discussion}

The aim of this study was to examine the relations between executive function (EF) components (i.e., inhibition and working memory) and academic performance among Taiwanese students in higher education. We found that both inhibition and working memory displayed non-significant associations with academic performance assessed by midterm exam scores, final exam scores and total scores in this sample. Our results are in line with previous research reporting no significant associations between EF components (i.e., inhibition and working memory) and academic performance among female college students in a mock study (Said, 2013), but in contrast to previous finding of better EF components (i.e., attention, planning, and self-control and selfmonitoring) being predictive of school success in first-year college students (Baars et al., 2015).

As to the associations between EF and academic performance, non-significances observed in our study and previous study (Said, 2013) may be explained by that participants' executive function skills were based on their self-reported questionnaires, which possibly reflected participants' ideal performance rather than actual performance (Said, 2013). Future studies using computerized tasks to examine executive function skills might be helpful to clarify this conjecture. Another reason for the non-significant relations in the present study could be the age distribution (Mean age $=26.72$, range $=18-50$ years, $\mathrm{SD}=10.62$ ) in our sample. As previous neuroimaging findings have shown that neuropsychological functions are under development until adulthood (around the age of 25) (Veroude, Jolles, Croiset, \& Krabbendam, 2013), the wide age range of our sample may obscure or weaken the associations between EF components and academic performance. Further studies are warranted to investigate whether or not the EF-academic performance associations vary by age groups. Moreover, Said (2013) found that college students' academic achievement was not related to EF components, but to metacognitive skills and time management. Combined with our results, these findings may suggest that relative to $\mathrm{EF}$ (e.g., working memory and inhibition), other variables such as time management and metacognitive skills are stronger contributors to academic performance for students in higher education. However, it is needed to note that this study only collected data on two EF components (i.e., working memory and inhibition). Therefore, it would be premature to conclude that EF is not significantly linked to academic performance among Taiwanese students in higher education. Other EF components need to be investigated in future research. Finally, as to the inconsistency between our findings and previous finding (Baars et al., 2015), which showed that executive functioning (i.e., attention, planning, and self-control and self-monitoring) was associated with study success in college students, this could be due to different constructs of EF and corresponding measures, sample characteristics, and assessments used to measure academic performance.

Although the current study advances our understanding on the associations between EF and academic performance among Taiwanese students in higher education, several limitations need to be taken into account. First, the sample is small and limited to students enrolled in an educational psychology course, which may limit the generalizability of the current findings to other samples with different demographic characteristics. Second, in the current study, participants' academic performance was measured by their test scores in an educational psychology course, which may not represent their overall academic performance or other types of academic performance.

In sum, despite of the lack of significant relations between EF components (i.e., inhibition and working memory) and academic performance in our sample, the current study may raise researchers' interests to further explore factors that contribute to academic performance in higher education and to replicate the present findings with some of the variables or constructs used in this study.

\section{References}

Ahmed, S. F., Tang, S., Waters, N. E., \& Davis-Kean, P. (2019). Executive function and academic achievement: Longitudinal relations from early childhood to adolescence. Journal of Educational Psychology, 111(3), 446458. doi:10.1037/edu0000296 
Baars, M. A., Nije Bijvank, M., Tonnaer, G. H., \& Jolles, J. (2015). Self-report measures of executive functioning are a determinant of academic performance in first-year students at a university of applied sciences. Front Psychol, 6, 1131. doi:10.3389/fpsyg.2015.01131

Best, J. R., Miller, P. H., \& Naglieri, J. A. (2011). Relations between executive function and academic achievement from ages 5 to 17 in a large, representative national sample. Learning and Individual Differences, 21(4), 327-336. doi:10.1016/j.lindif.2011.01.007

Blair, C. (2016). Executive function and early childhood education. Current Opinion in Behavioral Sciences, 10, 102-107. doi:10.1016/j.cobeha.2016.05.009

Blair, C., \& Razza, R. P. (2007). Relating effortful control, executive function, and false belief understanding to emerging math and literacy ability in kindergarten. Child Development, 78(2), 647-663. doi:10.1111/j.14678624.2007.01019.x

Espy, K. A., McDiarmid, M. M., Cwik, M. F., Stalets, M. M., Hamby, A., \& Senn, T. E. (2004). The contribution of executive functions to emergent mathematic skills in preschool children. Developmental Neuropsychology, 26(1), 465-486. doi:10.1207/s15326942dn2601_6

Fuhs, M. W., Farran, D. C., \& Nesbitt, K. T. (2015). Prekindergarten children's executive functioning skills and achievement gains: The utility of direct assessments and teacher ratings. Journal of Educational Psychology, 107(1), 207-221. doi:10.1037/a0037366

Garon, N., Bryson, S. E., \& Smith, I. M. (2008). Executive function in preschoolers: a review using an integrative framework. Psychological Bulletin, 134(1), 31-60. doi:10.1037/0033-2909.134.1.31

Holst, Y., \& Thorell, L. B. (2018). Adult executive functioning inventory (ADEXI): Validity, reliability, and relations to ADHD. International Journal of Methods in Psychiatric Research, 27(1). doi:10.1002/mpr.1567

Karr, J. E., Areshenkoff, C. N., Rast, P., Hofer, S. M., Iverson, G. L., \& Garcia-Barrera, M. A. (2018). The unity and diversity of executive functions: A systematic review and re-analysis of latent variable studies. Psychological Bulletin, 144(11), 1147-1185. doi:10.1037/bul0000160

Micalizzi, L., Brick, L. A., Flom, M., Ganiban, J. M., \& Saudino, K. J. (2019). Effects of socioeconomic status and executive function on school readiness across levels of household chaos. Early Childhood Research Quarterly, 47, 331-340. doi:10.1016/j.ecresq.2019.01.007

Miyake, A., Friedman, N. P., Emerson, M. J., Witzki, A. H., Howerter, A., \& Wager, T. D. (2000). The unity and diversity of executive functions and their contributions to complex "Frontal Lobe" tasks: a latent variable analysis. Cognitive Psychology, 41(1), 49-100. doi:10.1006/cogp.1999.0734

Montoya, M. F., Susperreguy, M. I., Dinarte, L., Morrison, F. J., San Martín, E., Rojas-Barahona, C. A., \& Förster, C. E. (2019). Executive function in Chilean preschool children: Do short-term memory, working memory, and response inhibition contribute differentially to early academic skills? Early Childhood Research Quarterly, 46, 187-200. doi:10.1016/j.ecresq.2018.02.009

Morgan, P. L., Farkas, G., Wang, Y., Hillemeier, M. M., Oh, Y., \& Maczuga, S. (2019). Executive function deficits in kindergarten predict repeated academic difficulties across elementary school. Early Childhood Research Quarterly, 46, 20-32. doi:10.1016/j.ecresq.2018.06.009

Ng, F. F.-Y., Tamis-LeMonda, C., Yoshikawa, H., \& Sze, I. N.-L. (2015). Inhibitory control in preschool predicts early math skills in first grade:Evidence from an ethnically diverse sample. International Journal of Behavioral Development, 39(2), 139-149. doi:10.1177/0165025414538558

Said, N. (2013). Predicting academic performance: executive functions, metacognition, study strategies, and self-efficacy. Paper presented at the 2013 Orlando International Academic Conference, Orlando, USA.

St Clair-Thompson, H. L., \& Gathercole, S. E. (2006). Executive functions and achievements in school: Shifting, updating, inhibition, and working memory. Quarterly Journal of Experimental Psychology, 59(4), 745759. doi: $10.1080 / 17470210500162854$

Thorell, L. B., \& Nyberg, L. (2008). The childhood executive functioning inventory (CHEXI): a new rating instrument for parents and teachers. Developmental Neuropsychology, 33(4), 536-552. doi:10.1080/87565640802101516

Thorell, L. B., Veleiro, A., Siu, A. F., \& Mohammadi, H. (2013). Examining the relation between ratings of executive functioning and academic achievement: findings from a cross-cultural study. Child Neuropsychology, 19(6), 630-638. doi:10.1080/09297049.2012.727792 
Veroude, K., Jolles, J., Croiset, G., \& Krabbendam, L. (2013). Changes in neural mechanisms of cognitive control during the transition from late adolescence to young adulthood. Dev Cogn Neurosci, 5, 63-70. doi:10.1016/j.den.2012.12.002

Welsh, M. C., \& Pennington, B. F. (1988). Assessing frontal lobe functioning in children: Views from developmental psychology. Developmental Neuropsychology, 4(3), 199-230. doi:10.1080/87565648809540405 